\title{
AGRIBISNIS SAGU UBI KAYU DI KELURAHAN JAYA, KECAMATAN TIDORE UTARA, TIDORE KEPULAUAN
}

\author{
Disusun Oleh : \\ FATMAWATI KADDAS, SP. M.Si
}

\begin{abstract}
Cassava in Indonesia has been developed since long time ago considering this plant has been a staple of the Indonesian population as well as rice and corn. In Jaya village, Tidore islands, predominantly they processing cassave into refined products of cassava starch commonly known as sago kasbi, this activity has been occupied for generations. This study aims to determine the production and marketing of cassava starch, knowing the cost and revenue, and determine the level of cassava starch feasibility. Research was conducted during the months of April to September 2012, located in the Jaya Village, North Tidore District, Tidore islands. The sampling method used in this study was purposive simple method by the number of respondents who were taken by $20 \%$ which is 27 respondents of 134 person who seek cassava starch. The research results obtained is the analysis of the average cost respondent worth Rp. 478,040.93, while the revenue earned by the respondent amounted to Rp. 333,070.19, while the calculation of the $\mathrm{R} / \mathrm{C}$ ratio average at 1.72 and $\pi / \mathrm{C}$ Ratio at 61.76 , with the income of the average respondent of cassava starch processing, the business is worth to be developed. So, there is a need for the development of cassava starch product diversity and product storage container so that production can be routinely obtained thus revenue can also be increased.
\end{abstract}

Keywords: Agribusiness cassava starch

\section{PENDAHULUAN \\ Latar Belakang}

Pengembangan agribisnis

merupakan salah satu bidang yang

diprioritaskan dalam program

pembangunan. Hal ini disebabkan agribisnis merupakan sektor yang direkomendasikan dalam program pembangunan nasional sebagai sektor unggulan guna menunjang kesejahteraan rakyat. Ketika sektor industri dan jasa mengalami tekanan berat saat krisis moneter melanda Indonesia, saat itu satu-satunya sektor yang masih mampu bertahan dan dapat diandalkan adalah sektor pertanian melalui pendekatan sistem agribisnis.

Guna mendorong upaya penciptaan sektor pertanian yang tangguh maka pemanfaatan sumberdaya alam yang berbasis agribisnis perlu diarahkan untuk mencapai tujuan dengan 
memanfaatkan ketersediaan lahan pertanian guna menunjang peningkatan sumber pangan seperti jenis tanaman ubi kayu (Manihot utilisima) yang kaya karbohidrat untuk dikelola menjadi jenis makanan.

Pengembangan jenis tanaman ubi kayu di Indonesia sejak dahulu sudah dikembangkan mengingat tanaman ini telah menjadi makanan pokok penduduk Indonesia disamping tanaman padi dan jagung. Berdasarkan pada pokok pikiran ini maka jenis tanaman ubi kayu dari segi pendekatan gizi dapat dikembangkan sebagai jenis tanaman sumber kalori, disamping itu jenis tanaman ini dapat dikelola menjadi pakan ternak dan pakan ikan, sebagai komoditas agroindustri seperti pembuatan produk tapioka, industri vermentasi dan berbagai industri makanan seperti gaplek.

Di Indonesia tanaman ubi kayu banyak dikembangkan sehingga tumbuh luas dan beradaptasi pada semua jenis tanah pertanian baik di dataran rendah maupun dataran tinggi yakni $10 \mathrm{~m}$ $1.500 \mathrm{~m}$ dpl dan di daerah beriklim panas atau tropis (Rahmat.R, 1997). Berdasarkan potensi fisik seperti kesesuaian lahan dan iklim, maka jenis tanaman ubi kayu ini dapat diusahakan pengembangannya di Maluku Utara khususnya di wilayah Tidore Kepulauan. Selama ini pengembangan tanaman ubi kayu diwilayah Tidore Kupulauan telah menunjukan hasil yang sangat memuaskan, ini dapat dilihat dari pengembangan jenis tanaman ubi kayu yang banyak diusahakan oleh masyarakat baik untuk dikonsumsi sebagai makanan maupun untuk dikembangkan menjadi produk olahan. Data yang diperoleh dari Dinas Pertanian dan Kehutanan Kota Tidore Kepulauan menunjukan angka produksi tanaman ubi kayu seperti terlihat pada tabel dibawah.
Tabel 1. Data Produksi dan Produktifitas Tanaman Ubi Kayu di Kota Tidore Kepulauan dari Tahun 2006-2010.

\begin{tabular}{|l|l|l|l|}
\hline $\begin{array}{l}\text { TAHU } \\
\mathrm{N}\end{array}$ & $\begin{array}{l}\text { LUAS } \\
\text { LAHA } \\
\text { N } \\
\text { /ha }\end{array}$ & $\begin{array}{l}\text { PRODUK } \\
\text { SI } \\
\text { /Ton }\end{array}$ & $\begin{array}{l}\text { PRODUK } \\
\text { TIVITAS/T } \\
\text { on }\end{array}$ \\
\hline 2006 & 302 & 32 & 0,1 \\
\hline 2007 & 322 & 1097 & 3,4 \\
\hline 2008 & 322 & 1097 & 3,4 \\
\hline 2009 & 572,1 & 546,6 & 0,95 \\
\hline 2010 & 599,4 & 788,3 & 1,31 \\
\hline
\end{tabular}

Sumber : Dinas Pertanian dan Kehutanan Kota Tidore Kepulauan, 2012.

Berdasarkan data diatas menunjukkan bahwa produksi tanaman ubi kayu selalu mengalami fluktuatif maka dengan ini sebagai upaya untuk meningkatkan produk ubi kayu sudah saatnya diterapkan kepada para petani di Kelurahan Jaya Tidore Kepulauan, hal ini sangat beralasan karena di desa tersebut upaya pengembangan tanaman ubi kayu menjadi produk olahan sagu yang lebih dikenal oleh masyarakat dengan nama sagu kasbi. Pengolahan sagu kasbi ini sudah dilakukan sejak turun temurun hingga sekarang sebagai makanan pokok dan juga sebagi mata pencaharian masyarakat di Kelurahan Jaya Tidore Kepulauan.

\section{Rumusan masalah}

Berdasarkan gambaran tersebut maka dapat diuraikan permasalahan bagaimana agribisnis sagu ubi kayu di Kelurahan Jaya ditinjau dari segi pengembangan produksi, biaya, pendapatan dan distribusi pemasaran produksi sagu ubi kayu serta tingkat kelayakan usaha. 


\section{Tujuan dan Kegunaan Penelitian}

Penelitian ini bertujuan untuk mengetahui jumlah produksi, biaya dan pendapatan serta tingkat kelayakan usaha sagu ubi kayu di Kelurahan Jaya Kecamatan Tidore Utara Kota Tidore Kepulauan.

Hasil penelitian ini diharapkan dapat memberikan informasi bagi home industri sagu ubi kayu di Kelurahan Jaya Kecamatan Tidore Utara Kota Tidore Kepulauan mengenai tingkat kelayakan usaha yang di tekuni disamping sebagai masukan yang sangat penting bagi penulis sebagai bahan acuan dalam pengembangan ilmu pengetahuan khususnya menyangkut kewirausahaan.

\section{METODE PENELITIAN}

Tempat dan Waktu Penelitian

Penelitian ini berlangsung selama bulan April sampai September tahun 2012. Lokasi penelitian bertempat di Kelurahan Jaya Kecamatan Tidore Utara Kota Tidore Kepulauan Provinsi Maluku Utara.

\section{Jenis dan Sumber data}

Adapun jenis data yang digunakan dalam penelitian ini yaitu data primer data sekunder. Data primer diperoleh langsung dengan wawancara dengan menggunakan kousioner, sementara data sekunder diperoleh dari dinas terkait dan referensi lainnya.

\section{Metode Pengambilan Sampel}

Metode pengambilan sampel yang digunakan dalam penelitian ini adalah metode purposive sample atau sampel bertujuan yaitu sampel yang dipilih secara sengaja pada produsen sagu ubi kayu yang ada Kelurahan Jaya Kecamatan Tidore Utara. Responden yang diambil sebanyak 20\% yaitu 27 responden dari 134 responden yang mengusahakan sagu ubi kayu.

\section{Metode Analisis Data}

\section{Analisis Biaya}

Untuk mengetahui seberapa besar biaya produksi yang dikeluarkan oleh pengelola usaha sagu ubi kayu, maka perlu dilakukan perhitungan biaya yang dikeluarkan untuk masing-masing input. Untuk menghitung total biaya yang dikeluarkan tersebut secara matematis dapat dihitung dengan memakai rumus sebagai berikut (Firdaus, 2008).

$\mathbf{T C}=\mathbf{F C}+\mathbf{V C}$

Dimana: $\mathrm{TC}=$ Total cost $/$ total biaya

$\mathrm{FC}=$ Fixed cost/biaya tetap

$\mathrm{VC}=$ Variabel cost $/$ Biaya variable

\subsubsection{Analisis Penerimaan}

Untuk menghitung tingkat penerimaan yang diperoleh pengusaha dalam memasarkan produk sagu ubi kayu yaitu:

\section{$\mathbf{T R}=\mathbf{P} \times \mathbf{Q}$}

Dimana: $\mathrm{TR}=$ Total Revenue/ Penerimaan Total

$\mathrm{P}=$ Price /Harga barang

$\mathrm{Q}=$ Quantity/Jumlah barang 


\section{Analisis Pendapatan}

Untuk menghitung pendapatan usaha Sagu Ubi Kayu, maka formula yang digunakan adalah ( Ken. S, 2006) sebagai berikut:

\section{Pendapatan $=$ Total Penerimaan - Total Biaya ( TR ) - ( TC)}

\section{Analisis Kelayakan Usaha}

Untuk menghitung kelayakan usaha Sagu Ubi Kayu digunakan beberapa kriteria, diantaranya perhitungan R/C Ratio (Return Cost Ratio) dan $\pi / \mathrm{C}$ Ratio. R/C Ratio yaitu perbandingan antar penerimaan dengan total biaya yang dikeluarkan oleh perusahaan, sedangkan $\pi / \mathrm{C}$ Ratio (produktifitas modal) yaitu perbandingan antara keuntungan dengan total biaya (Ken. S, 2006).

\section{Total Penerimaan}

\section{R/C Ratio $=$ Total Biaya}

Keterangan: R/C Ratio > 1 Usaha Mendapatkan Laba

R/C Ratio = 1 Usaha Seimbang

R/C Ratio $<1$ Usaha Rugi

Keuntungan $\pi / \mathbf{C}$ Ratio $=$ Total Biaya Keterangan: $\pi / \mathrm{C}$ Ratio $>$ bunga bank yang berlaku

\section{HASIL DAN PEMBAHASAN}

\section{Identitas Responden}

\section{Umur Responden}

Umur juga akan berpengaruh pada kecepatan menerima inovasi yang dianjurkan sehingga dengan kemampuan fisik dan penerapan inovasi diharapkan mampu menghasilkan produksi yang lebih besar dan berkualitas. Untuk lebih jelasnya dapat dilihat klasifikasi umur responden yang mengusakan sagu ubi kayu di Kelurahan jaya, Kota Tidore.

Tabel 2. Identitas Responden Berdasarkan Tingkat Umur dan Persentase di Kelurahan Jaya, Kecamatan Tidore Utara, Kota Tidore Kepulauan, 2012.

\begin{tabular}{|l|l|l|l|}
\hline No & \multirow{2}{*}{ Umur/th } & \multicolumn{3}{|l|}{ Produsen } \\
\cline { 3 - 4 } & & Orang & $\%$ \\
\hline 1 & $27-36$ & 7 & 25,9 \\
\hline 2 & $31-46$ & 14 & 51,9 \\
\hline 3 & $47-55$ & 6 & 22,2 \\
\hline
\end{tabular}

Sumber : Data primer yang diolah, 2012.

Data Tabel 2 menunjukkan bahwa responden yang mengelola sagu ubi kayu berdasarkan tingkat umur berbeda-beda, dimana tingkat umur yang terbesar yaitu $37-46$ tahun sejumlah 14 orang dengan tingkat persentase $51,9 \%$ sedangkan yang tingkat umur 47 - 55 tahun hanya sejumlah 6 orang atau persetase 22,2\%. Pada kisaran umur tersebut menunjukkan bahwa rata-rata umur responden tergolong produktif karena dalam pengolahan sagu ubi kayu dibutuhkan tenaga yang berpengalaman dan cukup kuat sehingga mendapatkan produksi yang banyak.

\section{Tingkat Pendidikan Responden}

Pendidikan responden sangat berpengaruh dalam pengolahan suatu usaha, karena akan mempengaruhi cara berfikir dalam menjalankan usahanya. Produsen yang mempunyai pendidikan yang telatif tinggi, akan membantu cara berfikir yang menyebabkan usahanya lebih efektif dan efisien. Untuk mengetahui lebih jelas tentang tingkat pendidikan responden dapat di lihat pada Tabel 3. 
Tabel 3. Identitas Responden Berdasarkan Tingkat Pendidikan di Kelurahan Jaya, Kecamatan Tidore Utara, Kota Tidore Kepulauan, 2011.

\begin{tabular}{|l|l|l|l|}
\hline No & \multirow{2}{*}{ Pendidikan } & \multicolumn{2}{|l|}{ Produsen } \\
\cline { 3 - 4 } & & Orang & $\mathbf{\%}$ \\
\hline 1. & Tidak & - & - \\
2. & Sekolah & 13 & 48,1 \\
3. & SD & 10 & 37.0 \\
4. & SLTP/SMP & 4 & 14,8 \\
& SLTA/SM & & \\
& A & & \\
\hline $\begin{array}{l}\text { Juml } \\
\text { ah }\end{array}$ & $\mathbf{2 7}$ & $\mathbf{1 0 0}$ & \\
\hline
\end{tabular}

Sumber : Data primer yang diolah, 2012.

Data Tabel 3 dijelaskan bahwa sebagian besar responden yang mengelolah sagu ubi kayu mempunyai latar belakang pendidikan tingkat Sekolah dasar (SD) yaitu sebanyak 13 orang atau $48.1 \%$ sedangkan tingkat pendidikan SMA terdapat 4 orang atau $14,8 \%$. Tingkat umur tiap responden sangat berpengaruh terhadap kemampuan dalam menerima inovasi baru disamping pengalaman yang dimiliki dalam usaha meningkatkan hasil produksi dan pendapatan.

\section{Pengalaman Usaha Responden}

Pengalaman usaha merupakan salah satu aspek yang penting dalam mendukung kelancaran suatu usaha, sebab pengalaman usaha sangat berperan dalam pengambilan keputusan dalam menjalankan usahanya untuk mencapai tujuan yang diharapkan. Untuk mengetahui lebih jelas tentang pengalaman usaha responden dapat dilihat pada Tabel 4.

Tabel 4. Identitas Responden berdasarkan pengalaman usaha, di Kelurahan Jaya,
Kecamatan Tidore Utara, Kota Tidore Kepulauan, 2011.

\begin{tabular}{|c|c|c|c|}
\hline \multirow[t]{2}{*}{ No } & \multirow{2}{*}{$\begin{array}{l}\text { Pengalaman } \\
\text { (Thn) }\end{array}$} & \multicolumn{2}{|c|}{ Produsen } \\
\hline & & Orang & $\%$ \\
\hline 1. & $5-13$ & 9 & 33,3 \\
\hline 2. & $14-22$ & 8 & 29,6 \\
\hline 3. & $23-27$ & 10 & 37,0 \\
\hline Jumlah & 27 & \multicolumn{2}{|l|}{100} \\
\hline
\end{tabular}
2012.

Data Tabel 4 menunjukkan bahwa pengalaman pembuatan sagu ubi kayu tiap responden di Kelurahan Jaya ada yang berpengalan hingga 27 tahun, ini menunjukkan bahwa responden telah mempunyai pengalaman yang cukup dalam mengelolah usahanya. Mengingat karena usaha sagu ubi kayu sudah dijalankan sejak turun temurun maka dengan pengalaman tersebutlah responden dapat menghasilkan sagu ubi kayu hingga saat ini.

Tabel 5. Identitas Responden Berdasarkan Jumlah Tanggungan Keluarga, di Kelurahan Jaya, Kecamatan Tidore Utara, Kota Tidore Kepulauan, 2012.

\begin{tabular}{|l|l|l|l|}
\hline \multirow{2}{*}{ No } & \multirow{2}{*}{$\begin{array}{l}\text { Jumlah } \\
\text { tanggungan } \\
\end{array}$} & \multicolumn{2}{|l|}{ Responden } \\
\cline { 3 - 4 } & (Orang) & Orang & $\mathbf{\%}$ \\
\hline 1. & $3-5$ & 22 & 81,5 \\
2. & $6-8$ & 5 & 18,5 \\
\hline Jumlah & $\mathbf{2 7}$ & $\mathbf{1 0 0}$ & \\
\hline
\end{tabular}

Sumber : Data primer yang diolah, 2012.

Data tabel 5 menunjukkan bahwa persentase jumlah tanggungan keluarga yang terbanyak adalah kisaran 3-5 orang atau $81,5 \%$, sementara jumlah tanggungan yang banyak yaitu $6-8$ orang menunjukkan persentase $18,5 \%$. Dengan demikian tuntutan pemenuhan 
kebutuhan hidup keluarga motivasi responden dalam meningkatkan produktifitasnya antara lain meningkatkan produksi sahu ubi kayu.

\section{Produksi}

\section{Jumlah Produsi Sagu Ubi Kayu}

Alur produksi pembuatan sagu ubi kayu dimulai dengan penyiapan bahan baku yaitu ubi kayu lalu dilanjutkan dengan proses pengkupasan dan pencucian selanjutnya dengan penggilangan hingga halus lalu dipres dan disaring agar diperoleh sari atau pati. Setelah tepung sagu sudah siap dilakukan pencetakan dan dilanjutkan dengan pembakaran sampai sagu matang.

Berdasarkan hasil penelitian pada tiap responden di Kelurahan Jaya rata-rata jumlah produksi yang diperoleh bervariasi dengan jumlah produksi yang paling sedikit 300 lempeng sagu sampai produksi yang besar 1200 lempeng sagu dengan jumlah bahan baku ubi kayu 2- 4 karung dalam satu kali proses produksi.

\section{Analisis Biaya dan Pendapatan Biaya}

Biaya dapat digolongkan dalam biaya variabel dan biaya tetap. Hasil penelitian menunjukkan bahwa untuk rata - rata penggunaan jenis biaya yang dikeluarkan tiap responden sebesar Rp. 148.148,15 untuk biaya variabel sedangkan biaya tetap yang terdiri dari penyusutan alat sebesar 329.892,78, sehingga diperoleh rata-rata total biaya dalam satu kali proses produksi

sebesar 478.040,93. Besarnya biaya yang dikeluarkan tiap responden berbeda berdasarkan jenis penggunaan bahan baku serta pemakaian peralatan yang dipergunakan.

\section{Pendapatan}

Berdasarkan hasil penelitian pada responden usaha sagu ubi kayu di Kelurahan Jaya total rata-rata pendapatan yang diperoleh tiap responden sebesar 333,07019. Yang mana diperoleh dari total penerimaan sebesar 811,111,11 dijumlah dengan total biaya sebesar 478,040,93.

\section{Analisis Kelayakan}

kelayakan artinya penelitian yang dilakukan secara mendalam yang dilakukan untuk menentukan apakah usaha yang akan dijalankan akan memberikan manfaat yang lebih besar dibandingkan dengan biaya yang akan dikeluarkan dengan kata lain usaha yang dijalankan itu akan memberikan keuntungan finansial sesuai dengan tujuan yang mereka inginkan, sehingga usaha tersebut layak dan dapat dikembangkan. Untuk melihat tingkat kelayakan usaha didasarkan beberapa kategori, dalam penelitian ini dipergunakan diantaranya analisis $\mathrm{R} / \mathrm{C}$ Ratio dan $\pi / \mathrm{C}$ Ratio.

\section{Analisis R/C Ratio}

Analisis R/C Ratio digunakan untuk melihat perbandingan antara total penerimaan dengan total biaya. Apabila nilai R/C Ratio > 1 maka usaha tersebut layak untuk dikembangkan. Berdasarkan penelitian yang dilakukan pada responden usaha sagu ubi kayu di kelurahan jaya menunjukkan rata-rata nilai R/C Ratio sebesar 1,72. Nilai tersebut menunjukkan bahwa usaha sagu ubi kayu layak untuk dikembangkan.

\section{Analisis $\pi /$ C Ratio}

Analisis $\pi / \mathrm{C}$ Ratio adalah perbandingan keuntungan yang diperoleh dengan total biaya yang dikeluarkan, dengan kriteria bahwa nilai $\pi / \mathrm{C}$ Ratio $>$ bunga bank yang berlaku. 
Berdasarkan penelitian yang dilakukan pada responden usaha sagu ubi kayu menunjukkan bahwa rata-rata $\pi / \mathrm{C}$ Ratio adalah senilai 61.76. Nilai tersebut masih lebih besar dari suku bunga bank yaitu sebesar 8\%. Data tersebut menunjukkan bahwa sagu ubi kayu perlu dikembangkan dengan penambahan penganeka ragaman produk sagu ubi kayu.

\section{KESIMPULAN}

Berdasarkan hasil penelitian pada tiap responden di Kelurahan Jaya rata-rata jumlah produksi yang diperoleh bervariasi dengan jumlah produksi yang paling sedikit 300 lempeng sagu sampai produksi yang besar 1200 lempeng sagu, dengan proses produksi yang sama yang dimulai dengan penyiapan bahan baku sampai proses pembakaran dan pengepakan.

Baya produksi yang dikeluarkan oleh responden sagu ubi kayu terdiri dari biaya variabel dan biaya tetap. Besar biaya variabel rata-rata Rp. 148.148,15 sedangkan biaya tetap ratarata tiap responden adalah Rp. 329.892,78. Biaya tiap responden berbeda-beda sesuai dengan tingkat kebutuhan responden dalam mengolah sagu ubi kayu.

Total pendapatan usaha selama satu kali proses produksi yaitu rata-rata sebesar Rp. 333,070.19, menunjukkan bahwa pendapatan yang di peroleh tiap responden dari hasil pengolahan sagu ubi kayu masih tergolong rendah disebabkan karena harga beli sagu ubi kayu oleh pedagang sangat murah, serta dipengaruhi juga oleh ketersediaan bahan baku yang belum optimal. Hasil perhitungan $\mathrm{R} / \mathrm{C}$ Ratio rata-rata sebesar 1,72. dan $\pi / \mathrm{C}$ Ratio sebesar 61.76 menunjukkan bahwa usaha sagu ubi kayu layak dan dapat dikembangkan.
DAFTAR PUSTAKA

Anonim, 2010. Mengembangkan makanan tradisional sagu kasbi. Sinar Tani Edisi No. 3415.

Anonim, 2010. Sagu kasbi pangan non beras dari ternate. BPTP Maluku Utara. BPS Kota Tidore. Kota Tidore Kepulauan Dalam Angka, 2006 - 2010. Data Base, 2010. Dinas Pertanian dan Kehutanan Kota Tidore Kepulauan.

Downey, W, 1987. Manajemen Agribisnis . Penerbit Erlangga, Jakarta. Firdaus M, 2008. Manajemen Agribisnis. Bumi Aksara, Jakarta Gumbira-Sa'id dkk, 2004. Manajemen Agribisnis, Ghalia Indonesia, Jakarta. Haryanto Tri dkk, 2009. Ekonomi Pertanian. Airlangga Unersity Press, Surabaya.

Kasmir, Jakfar, 2003. Studi Kelayakan Bisnis . Prenada Media Group, Jakarta.

Nina Nurani, 2007. Daya Saing Agribisnis. NUANSA, Bandung.

Rita Hanafie, 2010. Pengantar Ekonomi Pertanian. CV. ANDI OFFSET, Yogyakarta.

Rukmana Rahmat, 1997. Ubi Kayu, Budi Daya dan Pascapanen. Penerbit Kanisius, Yogyakarta.

Soekartawi , 2003. Teori Ekonomi Produksi. Grafindo Persada, Jakarta.

Suratiyah Ken, 2006. Ilmu Usahatani. Penebar Swadaya, Jakarta.

Sudiyono Arman, 2004. Pemasaran Pertanian. UMM Press, Malang.

Sudono Sukirno, 2004. Pengantar Teori Mikroekonomi . PT. RajaGrafindo Persada, Jakarta. 